\title{
TEKNOLOGI MOTOR BAKAR BENSIN UNTUK MENCAPAI PERSYARATAN BATAS MAKSIMAL POLUSI DAN EFISIENSI PEMAKAIAN BAHAN BAKAR BENSIN
}

\author{
Oleh \\ Nyoman Arya Wigraha \\ Jurursan Pendidikan Teknik Mesin Fakultas Teknik dan Kejuruan \\ Universitas Pendidikan Ganesha \\ Email: arya_wigraha@yahoo.co.id
}

\begin{abstract}
ABSTRAK
Sebagaimana yang telah diketahui bahwa semakin lama semakin meningkatnnya jumlah kendaraan bermotor yang beredar, baik itu kendaraan roda empat, dan yang mengalami peningkatan cukup tinggi adalah kendaraan bermotor roda dua. Di sini diharapkan kendaraan bermotor yang di produksi menggunakan teknologi untuk memenuhi persyaratan batas maksimal dari polusi yang ditimbulkan pada gas buang. Setiap pemakai kendaraan bermotor baik itu roda empat maupun roda dua tentunya mengharapkan dapat memiliki kendaraan yang hemat bahan bakar. Pengoperasian kendaraan oleh pemakai biasanya tidak akan mencapai hasil yang sama untuk segala kondisi pengoperasian, misalnya pengoperasian kendaraan pada kecepatan penuh sangat berbeda dengan kendaraan yang dioperasikan di dalam kota yang sering berhenti. Hal ini sangat menentukan pemakaian bahan bakar. Pengaturan pencampuran dan masuknya bahan bakar ke dalam silinder perlu dibedakan, antara operasi beban penuh dan operasi beban rendah atau menengah. Keadaan lingkungan yang makin menguatirkan, disebabkan oleh polusi udara dari kendaraan bermotor, mewajibkan para perencana dan produsen kendaraan bermotor untuk memenuhi persyaratan yang ditetapkan oleh pemerintah dan lembaga pengawas lingkungan. Standar yang disusun menuju pada suatu kondisi di mana kadar komponen-komponen gas buang yang beracun dan membahayakan kesehatan manusia, dibuat seminimal mungkin dan diusahakan mendekati nol. Agar tuntutan tersebut dapat dipenuhi, telah banyak dilakukan perubahan desain kendaraan bermotor. Beberapa contoh di antaranya yaitu menggunakan material yang lebih ringan, mengganti sistem penyemprotan bahan bakar, mengubah ketinggian pembukaan katup silinder dan waktu mulai buka dan lamanya pembukaan.
\end{abstract}

Kata Kunci: motor bensin, katalisator, katup, silinder

\begin{abstract}
As is well known that the longer the increasing number of vehicles in circulation, both fourwheeled vehicles, and the increase is high enough two-wheel motor vehicles. Here is expected in the production of motor vehicles that use the technology to meet the requirements of the maximum limits of pollution generated in the exhaust gases. Every motor vehicle user both four-wheel and two wheels can certainly expect to have a fuel-efficient vehicles. Operation of the vehicle by the user typically will not achieve the same results for all operating conditions, eg vehicle operation at full speed very different from the vehicles operated in the city that often stops. This will determine the fuel usage. Mixing arrangement and the entry of fuel into the cylinder is necessary to distinguish between full load operation and low or medium load operation. The environment is increasingly worrying, caused by air pollution from motor vehicles, obliging planners and motor vehicle manufacturers to meet the requirements set by the government and environmental monitoring agencies. Standards developed leading to a condition in which the levels of the components of the exhaust gases which are toxic and harmful to human health be minimized and cultivated close to zero. In order for these demands can be met, has done a lot of motor vehicle design changes. Some examples of these are using lighter materials, replace the fuel spraying systems, change the height of the opening of the cylinder valve and open the start time and duration of the opening.
\end{abstract}

Keywords:petrol engine, catalyst, cylinder valve

\section{Pendahuluan}

Semakin menipisnya cadangan bahan bakar minyak bumi di dunia, maka perlu 
dipikirkan berbagai cara untuk menghemat pemakaian bahan bakar dalam berbagai bidang. Telah banyak teknologi yang digunakan pada mesin motor bakar pada kendaraan untuk penggunaan bahan bakar minyak agar lebih efisien. Keadaan gas buang yang dapat mencemari lingkungan, merupakan kriteria yang paling penting dalam setiap pemikiran mengenai perubahan teknologi tersebut. Kendaraan di desain dengan bentuk yang lebih aerodinamis, penggunaan material yang lebih ringan untuk bagian kendaraan agar pemakaian bahan bakar dapat lebih efisien.

Motor bakar sendiri juga mengalami banyak perubahan dalam teknologi, misalnya penggunaan sistem injeksi dan turbo charger yang semakin banyak diaplikasikan pada kendaraan bermotor bensin dan pemilihan jenis material yang lebih ringan untuk komponen motor bakar dan juga di bagian body kendaraan, sehingga dapat lebih meningkatkan efisiensi bahan bakar Desain pengaturan udara dan bahan bakar perlu disempurnakan. Pengendalian atas jumlah udara yang masuk kedalam ruang pembakaran dengan demikian juga dapat mempengaruhi jumlah bahan bakarnya. Desain yang menggunakan cara penyemprotan bahan bakar secara langsung kedalam silinder juga telah dikembangkan. Selain itu, pengaturan pembukaan katub silinder secara bervariasi juga dapat membantu penghematan energi.

Dengan digunakannya turbo charger diperoleh penghematan bahan bakar, karena daya yang dihasilkan lebih besar, walaupun diameter silindernya lebih kecil. Penggunaan jenis material tertentu, seperti untuk komponen motor bakar dapat menurunkan berat motor per satuan daya $(\mathrm{kg} / \mathrm{kW})$, artinya dengan berat motor yang sama tetapi dihasilkan daya yang lebih tinggi. Komponen yang menggunakan material khusus ini adalah blok mesin menggunakan logam ringan yaitu paduan aluminium, pipa penghisap udara menggunakan bahan dari plastik, batang torak menggunakan jenis aluminium tertentu yang disebut RSAl(Rapidly Solified Aluminium), katup silinder menggunakan keramik. Rasio udara dan bahan bakar menentukan kesempurnaan pembakaran bahan bakar, makin banyak udara yang masuk kedalam karburator, maka makin banyak bahan bakar yang tertarik oleh kecepatan udara yang mengalir, apabila jumlah udara cukup besar maka kemungkinan terjadinya pembakaran yang sempurna akan lebih besar. Hal ini pada umumnya terjadi pada kondisi beban penuh, sedang pada kondisi beban setengah atau sebagian, jumlah udara tentunya lebih sedikit, sehingga kemungkinan ada bahan bakar yang tidak terbakar, tentunya hal seperti ini mengakibatkan pemborosan dan juga kondisi racun dari gas buang akan meningkat. Untuk mengatur jumlah udara yang masuk ke ruang pembakaran maka pengemudi kendaraan akan menginjak pedal gas, sebenarnya hal ini bukan untuk mengubah jumlah bahan bakar secara langsung, melainkan mengubah jumlah udara yang masuk melalui karburator. Pada kondisi setengah beban atau sebagian beban, posisi kelep kupu-kupu pada karburator adalah tertutup atau terbuka sebagian, tergantung 
dari seberapa dalam pengemudi menginjak pedal gas. Apabila beban sangat minimum misalnya pada saat kendaraan berhenti atau berada pada jalanan menurun, maka posisi kelep adalah menutup. Hal ini tentunya mengakibatkan terjadinya kevakuman pada saluran antara karburator dan silinder, karena torak tetap bergerak maka dia melakukan penghisapan udara. Kondisi se-macam ini merupakan suatu pemborosan energi, jadi untuk situasi semacam ini, penggunaan kelep tidak menguntungkan. Apa yang dapat dilakukan untuk meng- Gantikan kelep yang dapat mengatur jumlah udara yang masuk ke ruang silinder? Dengan mengatur katup silinder, maka jumlah udara dapat dikendalikan. Hal ini telah mulai diterapkan pada desain kendaraan BMW.

\section{Standar Emisi}

Perkembangan jumlah penduduk yang sangat menyolok di beberapa negara, menyebabkan meningkatnya kebutuhan akan tran- sportasi, khususnya kendaraan bermotor. Meledaknya jumlah kendaraan yang beroperasi di jalan raya, khususnya di daerah-daerah yang sangat padat penduduknya, ternyata mengakibatkan berapa masalah yang sangat menguatirkan. Di antaranya adalah meningkatnya kebutuhan akan bahan bakar dan pencemaran lingkungan oleh gas buang.

Beberapa negara maju yang sangat prihatin terhadap persoalan-persoalan ini menetapkan peraturan-peraturan yang harus dipenuhi oleh para pemakai dan penghasil kendaraaan bermotor. Negara bagian California di Amerika Serikat yang sangat merasakan kondisi udara yang sudah tidak bersih lagi, sejak tahun 1990 telah mulai menerapkan peraturan yang mewajibkan pengurangan polusi dengan membuat program kendaraan yang berpolusi rendah (low emision vehicle program). Sejak September 1990 negara bagian California membentuk suatu dewan yang disebut "Air Resources Board" yang bertugas menyusun peraturan-peraturan mengenai kendaraan yang berpolusi rendah dan bahan bakar yang bersih. Untuk mencapai tujuan dalam mendesain kendaraan ringan dan menengah yang berpolusi rendah sampai nol, maka ditetapkan empat kategori yang harus diikuti oleh para produsen kendaraan. Kategori ini adalah ken- daraan transisi berpolusi rendah (transitional low-emission vehicles), kendaraan berpolusi rendah (low-emission-vehicles), kendaraan berpolusi ultra rendah(ultra-low-emission vehicles) dan kendaraan berpolusi nol (zeroemission-vehicles). Keempat kategori ini harus dipenuhi secara bertahap dalam batas waktu yang telah ditetapkan, sehingga pada batas waktu terakhir, diharapkan agar kendaraankendaraan itu dapat mencapai kategori kendaraan berpolusi nol. Tabel di bawah ini menunjukkan standar yang dimiliki untuk masing-masing kategori, khususnya kadar gas organik bukan metan, karbon oksida dan oksida nitrogen. 
Tabel 1. Standar California untuk Polusi Dari

\section{Kendaraan Bermotor}

\begin{tabular}{|l|c|c|c|}
\hline Kategori & $\begin{array}{c}\text { Gas organik } \\
\text { bukan metan }\end{array}$ & $\begin{array}{c}\text { Karbon mono } \\
\text { oksida(CO) }\end{array}$ & $\begin{array}{c}\text { Oksida zat lemas } \\
\left(\mathrm{NO}_{\mathbf{x}}\right)\end{array}$ \\
\hline & gram/mil & gram/mil & gram/mil \\
\hline TLEV & 0,125 & 3,4 & 0,4 \\
\hline LEV & 0,075 & 3,4 & 0,2 \\
\hline ULEV & 0,04 & 1,7 & 0,2 \\
\hline ZEV & 0 & 0 & 0 \\
\hline
\end{tabular}

Bersamaan dengan apa yang dilakukan di Amerika Serikat, di Eropa juga berlaku pembatasan kadar gas buang, yaitu ditetapkan dalam standar EURO, di mulai dengan Euro 0, yang berlaku sejak 1988. Pembatasan yang ditetapkan adalah kadar oksida nitrogen, karbon mono oksida, hidro karbon dan butiran debu. Butiran debu dan NO merupakan komponen gas buang yang kritis. Untuk menurunkan kadar kedua komponen ini secara bersamaan tidak mudah. Penurunan kadar NO dapat dilakukan dengan menurunkan temperatur pembakaran, tetapi akibatnya butiran debu yang timbul dari karbon dan hidro karbon akan bertambah. Sebaliknya peningkatan temperatur pembakaran dapat mengurangi butiran debu, tetapi menaikkan kadar NO . Ditinjau dari konsumsi bahan bakar, temperatur pembakaran yang tinggi menghasilkan efisiensi pembakaran yang bagus, dengan demikian tercapai juga penghematan bahan bakar, tetapi kadar NO akan meningkat. Apabila temperatur diturunkan akan terjadi hal yang sebaliknya Mengingat akan hal tersebut di atas, maka perlulah dicari suatu jalan keluar yang mampu menyelesaikan persoalan ini.

\section{Udara dan Bahan Bakar}

\subsection{Kebutuhan udara untuk pembakaran}

Pada setiap pembakaran bahan bakar dibutuhkan sejumlah oksigen, yang diambil dari udara, jumlah udara teoritis yang di butuhkan adalah $14,7 \mathrm{~kg}$ untuk setiap $1 \mathrm{~kg}$ bahan bakar. Reaksi kimia dari pembakaran elemen karbon dan hidrogen adalah :

$\mathrm{C}+\mathrm{O}_{2}=>\mathrm{CO}_{2}$

$\mathrm{H}_{2}+1 / 2 \mathrm{O}_{2}=>\mathrm{H}_{2} \mathrm{O}$

Reaksi kimia pada pembakaran bensin yang merupakan campuran dari hidro karbon dengan penambahan belerang dan Nitrogen $(\mathrm{N})$ adalah :

$\mathrm{CH}_{4}+2 \mathrm{O}_{2}=>\mathrm{CO}_{2}+2 \mathrm{H}_{2} \mathrm{O}$

JPTK, UNDIKSHA, Vol. 12, No. 2, Juli 2015 : 143-158 
Kadar belerang di dalam bahan bakar sangat tidak di harapkan karena dapat membentuk gas hjidro sulfat yang sangat beracun . kadar belerang di dalam bahan bakar pada waktu ini telah sangat dibatasi. Untuk mencari kebutuhan udara teoritis untuk sejumlah bahan bakar tertentu dilakukan dengan menghitung berat molekul dari komponen-komponen yang mengalami reaksi kimia.

$$
\begin{aligned}
& \mathrm{CH}_{4}+2 \mathrm{O}_{2}+=>\mathrm{CO}_{2}+2 \mathrm{H}_{2} \mathrm{O} \\
& 16 \mathrm{~g}+64 \mathrm{~g}=>44 \mathrm{~g}+36 \mathrm{~g}
\end{aligned}
$$

Untuk setiap gram bahan bakar di butuhkan oksigen sebanyak 4 gram. karena oksigen dari udara dan di dalam udara juga terdapat nitrogen $(\mathrm{N})$ dan komponen lain yang lebih sedikit kadarnya, maka dengan diketahuinya perbandingan kadar oksigen dan nitrogen dapat dicari kebutuhan udara teoritis kebutuhan udara teoritis adalah $4: 0,232=17,24 \mathrm{~g}$. Dengan demikian setiap gram bahan bakar membutuhkan secara teoritis $17,24 \mathrm{~g}$ udara, supaya terjadi pembakaran yang sempurna.

Rasio udara $: \lambda$

$\lambda=$ jumlah udara sesungguhnya /jumlah udara teoritis

Untuk $\lambda>1$ :

Pembakaran terjadi dengan sempurna, campuran udara dan bahan bakar jenis ini disebut campuran us pemakaian bahan bakar lebih irit.

Untuk $\lambda<1$ kondisi ini disebut campuran gemuk bahan bakar boros di gunakan untuk kondisi beban maksimum.

Agar standar polusi yang telah ditetapkan tidak dilampaui, pada umumnya kendaraan beroperasi dengan $\ddot{e}=1$, khususnya pada operasi dengan beban penuh. Untuk operasi dengan beban rendah dan menengah digunakan campuran kurus.

\subsection{Penyemprotan Bahan Bakar}

Ada 3 cara penyemprotan bahan bakar bensin:

1. Karburator(banyak digunakan sampai tahun 1992)

2. Multi point injection(mulai digunakan sejak akhir tahun 70 an sampai sekarang)

3. Penyemprotan langsung (Direct injection) (mulai dikembangkan dan diterapkan pada saat ini 


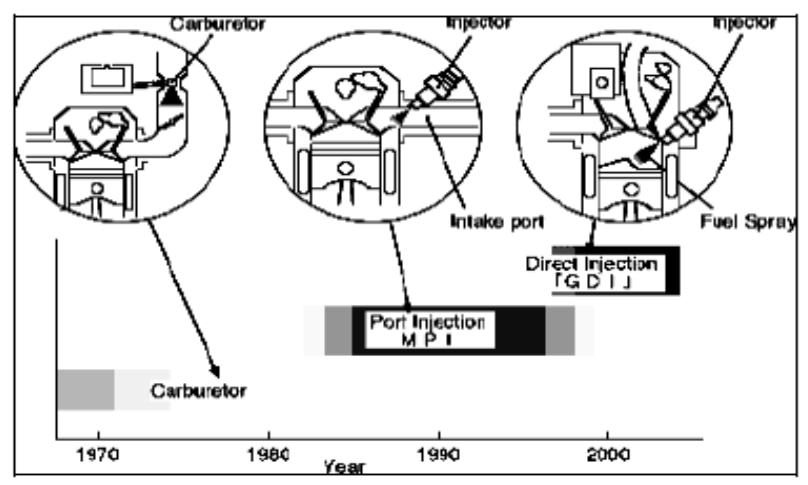

Gambar 1. Skema Tiga Jenis Penyemprotan Bahan Bakar

Sistem injeksi adalah cara penyemprotan bahan bakar dengan menggunakan alat semprot(injector) yang menggantikan karburator. Multi point injection adalah sistem penyemprotan bahan bakar dengan menggunakan injector, yang ditempatkan pada ujung-ujung pipa udara masuk (intake manifold) ke silinder. Sistem penyemprotan langsung menggunakan injector yang dipasang pada silinder sehingga semprotan bahan bakar segera berada di dalam silinder.

\subsubsection{Karburator}

Di dalam karburator bahan bakar yang dibutuhkan untuk pembakaran diatur, baik untuk kondisi beban penuh maupun beban kosong. Jumlah campuran udara dan bahan bakar yang akan disemprotkan kedalam silinder diatur melalui pedal gas yang menggerakkan katup kupu-kupu (throttle valve), sehingga banyaknya udara yang masuk melalui pipa venturi pada karburator dapat dikendalikan. Pipa venturi ini mengakibatkan kecepatan udara pada daerah venturi mengalami percepatan sedang tekanan mengalami penurunan. Perbedaan tekanan antara kamar apung (chamber) dan ujung pipa keluarnya bahan bakar (fuel jet) mengakibatkan bahan bakar disemprot keluar. Makin besar pembukaan kelep kupu-kupu, makin banyak udara mengalir melalui pipa venturi. Hal ini mengakibatkan, bahan bakar makin banyak mengalir keluar dalam bentuk pancaran butiran bahan bakar yang halus.

Dalam keadaan tanpa beban, kelep kupu-kupu menutup pipa saluran bahan bakar. Torak motor bakar melakukan gerak turun naik, melakukan kerja menghisap dan memompa, terutama menghisap suatu kevakuman. Kerja ini merupakan energi yang terbuang, sehingga posisi kelep tertutup ini merugikan. Mengingat akan hal ini, maka terpikirkan untuk menghapuskan penggunaan kelep kupu-kupu ini. 


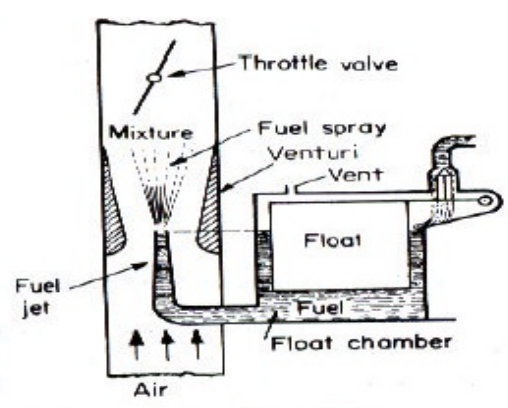

Carburetor for gasoline engine.

Gambar 2. Karburator

\subsubsection{Multi point injection}

Penyemprotan bahan bakar terjadi pada pipa pemasukan udara dan bahan bakar. Sistem ini yang banyak digunakan untuk menggantikan karburator. Berhubung pencampuran udara dan bahan bakar terjadi di pipa masuk dan bukan di silinder, maka pencampuran udara dan bahan bakar lebih homogen, pengaturan atas pembakaran masih sangat terbatas. Berhubung bahan bakar dan udara sudah bercampur pada saat memasuki ruang pembakaran, maka pengaturan untuk mengubah kondisi campuran dan pengaturan untuk proses pembakaran lebih sulit dilakukan.

\subsubsection{Penyemprotan Langsung (Direct injection)}

Sistem penyemprotan langsung pada motor bakar bensin ternyata dapat mengurangi konsumsi bahan bakar. Pada awalnya sistem ini digunakan untuk mendapatkan daya motor yang tinggi dan menghemat bahan bakar pada operasi beban maximum. Walaupun sistem penyemprotan langsung ini mampu menghemat bahan bakar dibandingkan sistem yang lain, tetapi kadar gas buangnya, yaitu butiran-butiran debu, oksida zat lemas (NO), hidro karbon (HC) dan karbon mono oksida (CO) masih belum dapat memenuhi tuntutan standar. EURO4 yang akan berlaku mulai 1 Januari

2005 menetapkan : $\mathrm{CO}: 1,0[\mathrm{~g} / \mathrm{km}]$

$$
\begin{gathered}
\mathrm{HC}: 0,1[\mathrm{~g} / \mathrm{km}] \\
\mathrm{NO}_{\mathrm{x}}: 0,1[\mathrm{~g} / \mathrm{km}]
\end{gathered}
$$

ZEV : $10 \%$ dari produksi kendaraan ringan harus memenuhi persyaratan ZEV, yaitu :

Gas organik bukan metan : $0[\mathrm{~g} / \mathrm{mil}]$

$\begin{array}{ll}\text { CO } & : 0[\mathrm{~g} / \mathrm{mil}] \\ \text { NO } & : 0[\mathrm{~g} / \mathrm{mil}]\end{array}$

Untuk mencapai standar kadar komponen gas buang, ada beberapa persyaratan yang harus dipenuhi oleh motor bakar dengan sistem

penyemprotan langsung. Motor bakar harus dilengkapi dengan katalisator pada 
saluran pipa pembuangan dan jenis bahan bakar tidak boleh terlalu banyak mengandung belerang. Sistem penyemprotan langsung memiliki karakteristik:

1. Arah arus udara yang masuk ke dalam silinder dan desain torak yang tepat, bersama-sama dengan penempatan injector yang tepat akan menghasilkan bola-bola campuran udara dan bahan bakar berkumpul di dekat busi menghasilkan suatu pembakaran yang sempurna.

2. Tidak dibutuhkan lagi kelep kupu-kupu, sehingga tidak ada energi yang terbuang.

\section{Gas Buang dan Katalisator}

Untuk memenuhi persyaratan tersebut, kendaraan motor bensin diperlengkapi dengan katalisator yang berfungsi untuk menurunkan kadar komponen tertentu, yaitu $\mathrm{CO}$, $\mathrm{NO}$, $\mathrm{HC}$ dan butiran-butiran debu. Pada gambar 3 dapat dilihat pemasangan katalisator untuk mengurangi komponen gas buang. Pada pipa pembuangan gas dari silinder di pasang sebuahsensor lambda (Lambda-Sonde), katalisator 3 jalan (drei - wege - Katalysator) dan katalisator penampung $\mathrm{NO}_{\mathrm{x}}\left(\mathrm{NO}_{x}\right.$-Speicher-Katalysator $)$ Sensor temperatur dan sensor $\mathrm{NO}_{\mathrm{x}}$. Sensor lambda bersama-sama dengan katalisator 3 jalan mengatur rasio udara/bahan bakar, melalui sebuah alat kontrol. Katalisator tiga jalan mampu menurunkan kadar tiga komponen, yaitu karbon monoksida $(\mathrm{CO})$, hidrokarbon $(\mathrm{CH})$ dan $\mathrm{NO}_{\mathrm{x}}$. Katalisator penyimpanan $\mathrm{NO}_{\mathrm{x}} \quad\left(\mathrm{NO}_{x}\right.$-Speicher- Katalysator $)$ berfungsi untuk menurunkan kadar $\mathrm{NO}_{\mathrm{x}}$. Pada campuran kurus komponen $\mathrm{NO}_{\mathrm{x}}$ disimpan oleh katalisator agar pada saat operasi normal dapat diubah menjadi $\mathrm{N}_{2}$. Sensor $\mathrm{NO}_{2}$ berfungsi untuk mendeteksi kadar $\mathrm{NO}_{\mathrm{x}}$ yang terdapat di dalam katalisator. Belerang yang terdapat pada bahan bakar dapat mengakibatkan katalisator tersumbat

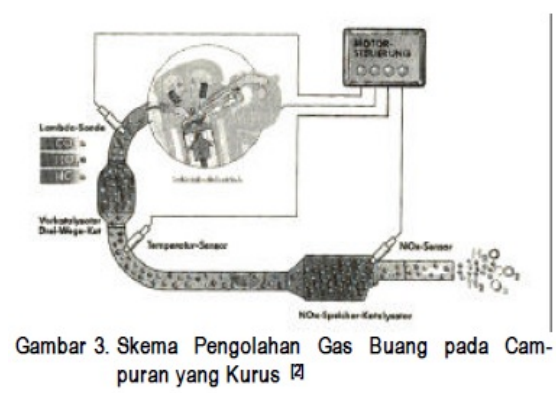

Pada pengoperasian motor dengan beban penuh, temperatur yang dihasilkan adalah $>650^{\circ} \mathrm{C}$, pada temperatur yang tinggi belerang dapat terdorong keluar. Pada pengoperasian beban rendah, temperatur tidak terlalu tinggi, sehingga katalisator tetap tersumbat. Belerang yang terdapat di dalam bahan bakar pada saat ini masih sangat tinggi $>500 \mathrm{ppm}$, sehingga sangat mengganggu katalisator. 

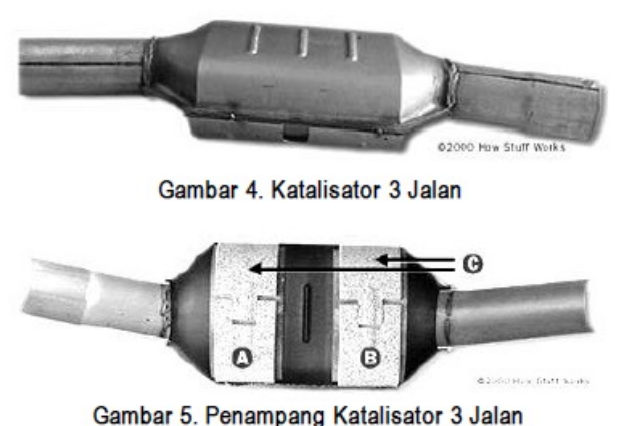

keterangan gambar :
A: Katalisator Reduksi
B: Katalisator Oksidasi
$\mathrm{C}:$ Keramik berbentuk sarang lebah

Katalisator 3 jalan terdiri dari katalisator reduksi (A) dan katalisator oksidasi (B), keduaduanya merupakan struktur keramik yang dilapisi oleh katalisator metal umumnya platinum, rhodium atau paladium. Keramik ini berbentuk sarang lebah (C). Katalisator reduksi dilapisi dengan platinum dan rhodium sebagai katalisator, berfungsi untuk menurunkan kadar NO . Apabila molekul NO atau NO menyentuh katalisator, atom nitrogen akan ditahan, sedang molekul oksigen dilepas.

Reaksi kimia :

$$
\begin{array}{ll}
2 \mathrm{NO} & \mathrm{N}+\mathrm{O} \\
2 \mathrm{NO} & \mathrm{N}+2 \mathrm{O}
\end{array}
$$

Katalisator oksidasi berfungsi untuk mengurangi hidro karbon yang tidak terbakar dan mono oksida karbon melalui katalisator platinum dan paladium. Oksigen yang terdapat di dalam pipa gas buang mengoksidasi $\mathrm{CO}$ dan hidro karbon menjadi CO dan air. Reaksi kimia $: 2 \mathrm{CO}_{2}+\mathrm{O}_{2}=>2 \mathrm{CO}_{2}$

\section{Pengaturan Pembukaan Katup Silinder}

Seperti telah dibahas sebelumnya bahwa dengan mengatur jumlah udara melalui kelep kupu-kupu ternyata kurang menguntungkan karena ada energi yang terbuang, khususnya apabila kelep tersebut dalam keadaan tertutup total. Kekurangan yang masih ada pada sistem penyemprotan langsung, yaitu ketergantungan sistem ini pada bahan bakar yang kadar belerangnya rendah, maka dibutuhkan cara lain yang lebih mampu mengatasi permasalahan polusi sekaligus mampu menghemat bahan bakar. Untuk menggantikan sistem ini, maka dikembangkan suatu sistem yang baru, yaitu pengaturan udara melalui katup silinder.

Ada 4 kemungkinan untuk mengubah gerakan katup silinder, yaitu :

1. Pergeseran fasa poros bubungan (cam shaft).

2. Perubahan jarak pembukaan katup. 
3. Variasi waktu buka atau tutup dari katup silinder.

4. Mematikan beberapa silinder dengan cara menutup karup Penghematan bahan bakar dan penurunan kadar gas buang seperti $\mathrm{CO}, \mathrm{CH}$, $\mathrm{NO}$ dan butiran-butiran debu, merupakan tujuan yang ingin dicapai oleh sistem yang baru, yaitu mengatur pembukaan katup silinder secara bervariasi tergantung dari beban yang dikehendaki. Untuk mendapatkan hasil yang diinginkan, maka semprotan bahan bakar yang alus harus segera bercampur dengan udara dan membentuk kabut awan yang mudah terbakar secara merata. Sistem ini harus memperhatikan agar bahan bakar yang berada di dalam ruang silinder dapat bercampur dengan udara secara merata, sehingga mudah dijangkau oleh api dari busi. Pembentukan campuran yang homogen terjadi dengan pengatur pembukaan katup tidak terlalu besar sehingga udara yang masuk memiliki kecepatan tinggi. Gerakan udara berbentuk pusaran juga membantu terjadinya campuran yang homogen. ada kondisi tanpa beban, terutama pada saat katup masuk menutup, sedang torak bergerak turun menuju titik mati bawah, volume ruang silinder membesar, maka campuran kehilangan gerakannya. Hal ini mengakibatkan pembakaran yang tidak sempurna, karena gerakan pembakaran melambat dan tidak merata. Untuk mengatasi hal ini, dibutuhkan masa pembakaran yang lebih cepat untuk mengatur jarak pembukaan katup disilinder digunakan bubungan, yang meng- erakkan lengan yang berhubungan dengan tangkai katup, sehingga posisi terbukanya katup sebanding dengan posisi bubungan. untuk mendapatkan jarak yang berbeda pada masing-masing katup, bentuk bubungan dapat didesain sesuai dengan kebutuhan akan tinggi rendahnya bukaan katup maupun posisi kapan katup mulai membuka atau menutup. hubungan yang berada pada poros bubungan dapat didesain secara kaku atau fleksibel, artinya tetap pada posisi atau dapat digeser pada porosnya. Berbeda dengan sistem karburator, poros bubungan selalu berada pada posisi yang tetap.

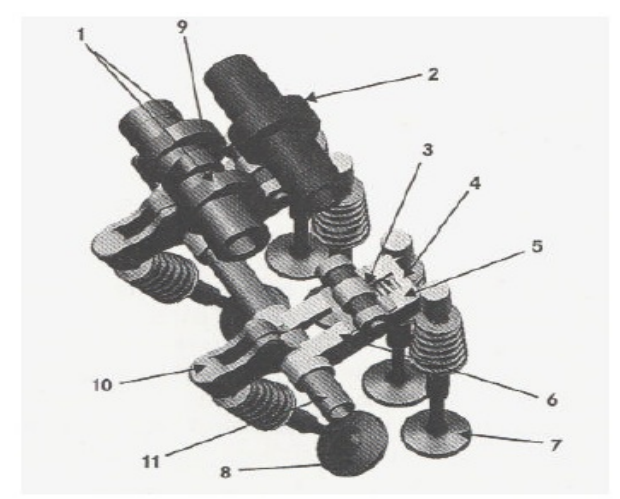

Gambar 6. Mekanisasi pengaturan pembukaan katup

Keterangan gambar 6:

1. Bubungan buka(katup masuk)

2. Bubungan tutup(katup masuk) 
3. Rol

4. Pegas pengatur

5. Tempat pegas

6. Lengan(katup masuk)

7. Katup masuk

8. Katup keluar

9. Bubungan(katup keluar

10. Lengan(katup keluar)

11. Poros penahan

Pada gambar di atas hubungan 1 dan 2 berada pada poros bubungan yang berbeda, bubungan 1 akan menekan lengan 6, sehingga tangkai katup akan ditekan kebawah sesuai posisi bubungan. Bubungan 2 berfungsi untuk menutup katup. Untuk mendapatkan putaran dan beban yang diinginkan, posisi bubungan harus tepat dan berfungsi dengan sempurna, untuk ini maka digunakan motor yang mampu memutar poros bubungan pada posisi yang tepat, seperti pada beberapa sistem yang akan dibahas lebih lanjut. Motor mendapat masukan dari kontrol yang dihubungkan dengan putaran motor.

\subsection{Valve-Timing and Lift Electronic Control (VTEC)}

Pengaturan yang digunakan oleh Honda disebut pengaturan waktu dan pembukaan katup secara elektronik atau disingkat VTEC. Perbedaan pengaturan katup pada sistemVTEC dibagi dalam 2 posisi atau lebih, yaitu pertama pada putaran rendah, fasa kedua pada putaran yang lebih tinggi, tergantung dari jenis sistem yang digunakan. Perubahan ini dapat terjadi pada putaran rendah, dan untuk posisi berikutnya $2500 \mathrm{rpm}$ dan posisi ketiga pada putaran $6000 \mathrm{rpm}$. Pembagian ini dilakukan, karena pada putaran yang lebih tinggi terjadi keterlambatan masuknya udara ke ruang pembakaran, sedang pada putaran rendah tidak terjadi keterlambatan masuknya udara tersebut. Mengingat akan hal tersebut, maka perlu dibedakan saat pembukaan katup untuk putaran yang berbeda. Pada putaran yang lebih tinggi, pembukaan katup dilakukan lebih awal, waktu pembukaan lebih lama dan jarak

pembukaan lebih tinggi. Pada kondisi putaran rendah, pembukaan katup tidak perlu terlalu dini, waktu lebih singkat dan jarak lebih pendek. Setiap silinder memiliki 4 katup dan bubungan yang menggerakkan lengan untuk mengatur pembukaan katup dengan cara menekan tangkai katup sesuai dengan bentuk bubungan. Pada setiap silinder terdapat 2 jenis bubungan, yaitu bubungan untuk pembukaan katup putaran rendah dan bubungan untuk putaran tinggi, kedua bubungan ini mempunyai bentuk berbeda. Bubungan berputar pada satu poros, bubungan pertama berfungsi pada putaran rendah sedang bubungan kedua baru akan berfungsi kalau putaran sudah mencapai ketinggian yang 
diprogramkan. Sistem ini mampu menghemat bahan bakar dan memberikan daya maksimum pada putaran tinggi

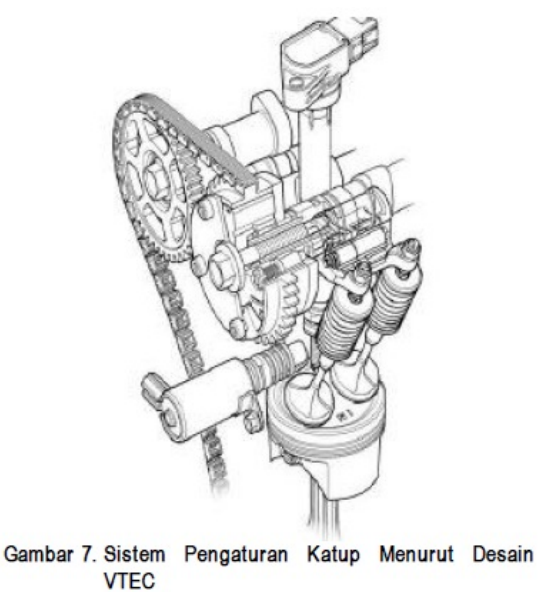

Kedua katup silinder mendapat tekanan kebawah melalui lengan yang ditekan oleh sebuah rol. Rol tersebut berhubung-an langsung dengan kedua bubungan. Pada putaran rendah bubungan yang lebih kecil yang beroperasi, sedang bubungan besar diam. Pada saat putaran mencapai ketinggian tertentu, maka melalui kontrol elektronik akan dialirkan melalui sebuah saluran yang terdapat di dalam poros bubungan, tekanan minyak yang mampu mendorong sebuah pasak sehingga posisi bu-bungan kedua akan terkunci. Bubungan kedua akan ikut berputar dan menggantikan fungsi bubungan pertama.

\subsection{Valvetronic}

Sistem terbaru yang pada saat ini telah diterapkan untuk produksi, yang dikembangkan oleh BMW adalah Valvetronic. Dalam mengembangkan sistem ini, penekanan diletakkan pada pengaturan beban dengan tanpa menggunakankelep kupu-kupu, yang sudah diketahui pada pembahasan sebelumnya, bahwa kelep ini tidak menguntungkan. Salah satu faktor yang juga merupakan pemikiran dalam desain yang pada saat ini sedang berkembang, adalah adanya kenyataan bahwa operasi kendaraan bermotor yang paling banyak dipakai terjadi pada operasi beban rendah dan menengah. Operasi beban penuh lebih jarang dimanfaatkan, terutama kendaraan yang beroperasi di dalam kota. Operasi motor pada kondisi kendaraan sedang berhenti atau beban menengah, memerlukan campuran kurus, yaitu $\ddot{e}<1$. Seperti diketahui pada campuran kurus bahan bakar dapat irit dan polusinya rendah. Pengaturan campuran dilakukan oleh pembukaan katup, dengan pembukaan yang kecil, kecepatan udara akan meningkat. Penyemprotan bahan bakar terjadi di pipa udara masuk sebelum masuk ke dalam silinder, seperti padamulti point injection, di sini tidak digunakan penyemprotan langsung, yang telah diketahui memiliki kelemahan. Pembukaan katup silinder secara statis dari $0,1 \mathrm{~mm}$ sampai $10 \mathrm{~mm}$, pada saat tanpa beban pembukaan sangat kecil, pada saat beban JPTK, UNDIKSHA, Vol. 12, No. 2, Juli 2015 : 143-158 
penuh pembukaan maksimum, bahan bakar yang disemprotkan ke daalam pipa udara masuk akan bercampur dengan udara. Pada operasi tanpa beban, berhubung lubang masuk sangat kecil dan terjadi penghisapan yang kuat dari torak, maka dapat terjadi pencampuran udara dan bahan bakar yang sangat homogen. Pembakaran terjadi sangat merata, sehingga hampir tidak ada polusi. Perbedaan dengan sistem yang lain, adalah sebuah tuas, yang digunakan sebagai pengganti bubungan, yang memiliki bentuk kurva pada ujungnya. Kurva pada ujung tuas berhubungan dengan rol pada lengan dan mampu menekan tangkai katup ke bawah dan membuka katup sesuai dengan jarak yang diharapkan.
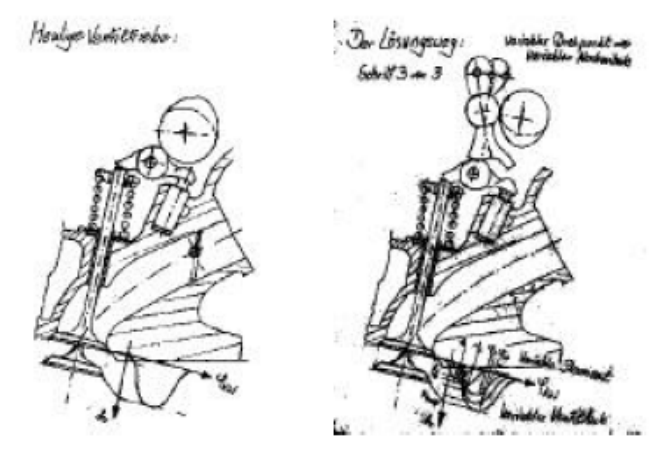

Gambar 8. Pengaturan Katup pada Motor Bakar Bensin

Pada kedua gambar di atas dapat dilihat perbedaan antara pengaturan katup yang banyak digunakan oleh motor bensin pada umumnya seperti terlihat pada gambar sebelah kiri, sedang pada gambar sebelah kanan adalah desain dari BMW.

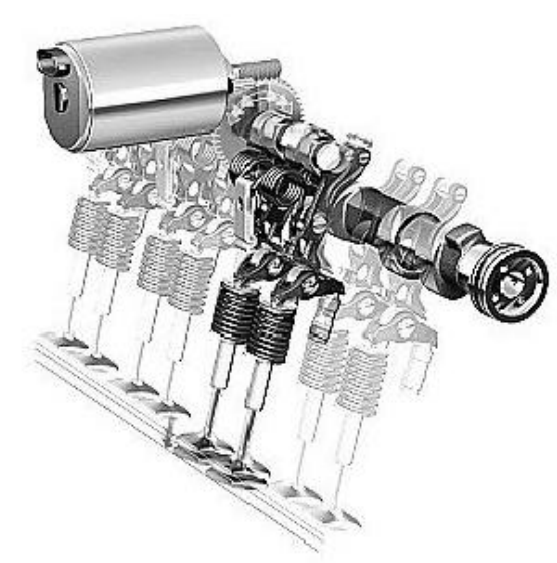

Gambar 9. Mekanisasi Pengatur Katup

Tuas dengan ujung yang berbentuk kurva mampu menggerakkan tangkai katup, sehingga jarak pembukaan dapat diatur bubungan yang berputar pada porosnya mampu 
menggerakkan tuas kekiri pada saat bubungan mendesak tuas, karena bentuk kurva dari ujung tuas maka mampu mendesak tangkai katup agar jarak bukaan makin besar pada ujung tuas sebelah atas dihubungkan dengan sebuah poros eksentrik. Poros eksentrik ini memberi kemungkinan pada tuas untuk bergerak lebih jauh ke kiri atau ke kanan, tergantung dari posisi eksenternya. untuk mengembalikan tuas pada posisi awal, maka disamping kiri tuas dilengkapi dengan sebuah pegas. Untuk menggerakkan poros eksentris digunakan sebuah motor. Untuk memperjelas bentuk tuas dan hubungannya dengan lengan, poros bubungan maupun poros eksentris dapat dilihat dengan jelas pada gambar berikutnya. dibandingkan dengan sistem yang lain,valvetronic mempunyai beberapa kelebihan, yaitu tidak tergantung pada jenis bahan bakar yang kadar belerangnya rendah. Penghematan bahan bakar menyamai sistem penyemprotan langsung, sedang polusi yang ditimbulkan sangat rendah, sehingga masih dapat memenuhi persyaratan standar EURO maupun california Standar(ULEV) yang berlaku pada saat ini. Salah satu kelemahan yang ada pada sistem ini, adalah keeterbatasannya untuk operasi motor di atas $6000 \mathrm{rpm}$. Pada putaran tinggi, karena mekanisme yang sangat rumit mengakibatkan timbul banyak gesekan antar komponen yang terlibat, sehingga dapat menurunkan efisiensi. Komponen-komponen yang digunakan pada sistem ini memiliki ketelitian yang sangat tinggi, sehingga memerlukan proses manufaktur yang mengarah pada produksi masal, agar biaya tidak tinggi.
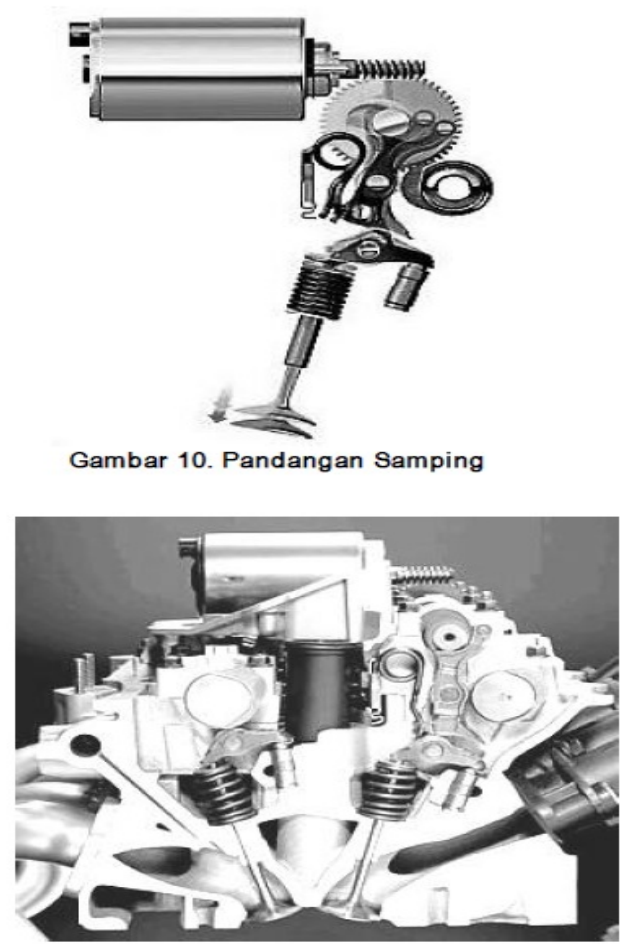
Gambar 11. Mekanisme Valvetronic Terpasang pada
Silinder Blok [10] 


\section{Penutup}

Desain kendaraan dan motor penggeraknya sangat dipengaruhi oleh faktor-faktor yang dapat merubah kondisi lingkungan hidup maupun tuntutan ekonomi. Komponen yang terdapat pada gas buang telah diketahui dapat mengakibatkan banyak masalah bagi kehidupan di dunia. Peraturan-peraturan yang dibuat oleh lembaga pemerintah mewajibkan setiap produsen motor dan kendaraan untuk selalu berusaha memenuhinya. Perkembangan yang dilakukan oleh para teknisi dan produsen telah merubah desain motor, dari penggunaan komponen yang menggunakan metal berat sampai kepada metal ringan dan plastik, membuat motor menjadi lebih ringan yang berakibat menguntungkan secara ekonomis. Tuntutan atas daya yang makin kuat dan bentuk yang makin ringkas, agar kendaraan mempunyai daya angkut yang lebih dan kecepatan tinggi maupun jarak tempuh, memberikan beban pikiran bagi para ahli, yang tidak akan pernah berhenti. Dari pembahasan di dalam naskah ini, dapatlah diikuti kemana arah yang sedang dituju oleh para teknisi dan peneliti untuk selalu mempersiapkan kebutuhan akan tenaga penggerak dimasa-masa yang akan datang.

Motor bensin yang pada awal mulanya menggunakan karburator telah mengalami perubahan, yaitu digunakannya penyemprotan baik pada pipa udara masuk maupun yang sekarang sedang mulai dikembangkan, penyemprotan langsung ke dalam silinder. Perubahan ini telah membawa keuntungan ekonomis, karena terjadi penghematan bahan bakar.Perkembangan dibidang motor diimbangijuga dengan perkembangan di bidang bahan bakar, seperti telah diketahui bahan bakar pada umumnya mengandung kadar belerang yang sangat tinggi. Berhubung belerang ini dapat merusak katalisator yang mempunyai fungsi untuk menurunkan kadar komponen dalam gas buang, maka bahan bakar harus dibatasi kadar belerangnya, untuk saat ini kadar belerang sebesar 30 ppm kebawah sangat diharapkan. Katalisator sudah merupakan keharusan pada kendaraan yang diwajibkan untuk memenuhi standar gas buang baik kendaraan ini dipergunakan di Eropa, Amerika atau negara maju lainnya. Pengoperasian kendaraan pada beban rendah dan menengah, terutama kendaraan yang lebih banyak digunakan di dalamkota tentunya berbeda dengan kendaraan yang beroperasi di luar kota dengan beban maksimum. Pada beban rendah, campuran udara dan bahan bakar adalah kurus, sedang untuk operasi beban penuh, campuran gemuk. Berhubung kelep kupu-kupu yang biasanya digunakan untuk mengatur campuran, ternyata memiliki kerugian, maka digunakan cara pengaturan yang lain, yaitu pengaturan melalui pembukaan katup silinder, secara bervariasi. Dengan pembukaan yang sangat kecil kira-kira 0,1 sampai $0,3 \mathrm{~mm}$, dapat diperoleh campuran yang homogen, sehingga polusinya rendah, hal ini dilakukan untuk operasi beban kosong, misalnya kendaraan sedang tidak bergerak, menunggu muatan. Sistem pengaturan campuran dengan melalui katup telah dilakukan oleh pembuat motor bensin, di antaranya Honda dengan sistem VTEC yang 
telah beroperasi lebih dari 8 tahun dan mampu memberikan andil yang cukup baik. Sistem terbaru yang dikembangkan oleh BMW, yaitu Valvetronic memberi keuntungan lebih banyak dari segi penghematan bahan bakar dan kondusi kadar polusi yang dapat memenuhi persyaratan yang ditetapkan pada waktu ini. Masih banyak perkembangan yang dapat terjadi, hal ini tidak luput dari peran elektronik dan tehnologi informasi, seperti komputer, yang telah banyak berperan dalam sistem pengaturan pada kendaraan dan motor bensin, terutama dalam pengontrolan bahan bakar.

\section{DAFTAR PUSTAKA}

Bolt J.A., Cole D.E., Mirsky W., Patterson D.J., "Internal Combustion Engines", Mark's Standard Handbook for Mechanical Engineers, ninth Edition, McGraw Hill Book Company, New York, 1987.

Schommers J, Duvinage F. dan Kemmler R., "Entwicklungsperspektiven von Kraftfahrzeugantrieben" - Jahrbuch 2000 - Fahrzeug-und Verkehrstechnik, VDI Verlag GmbH, Düsseldorf, 2000.

Neumann K.H., Schindler K.P., "Future powertrain concepts"- Jahrbuch 2001 Fahrzeug- und Verkehrstechnik, VDI Verlag GmbH, Düsseldorf, 2001.

Wildhage H.J., "Verschärfte Abgasgrenz-werte führen zu Ziekonflikten", VDI Nachrichten, 8. September 2000.

Wildhage H.J., "Benziner fährt mager amweitesten", VDI Nachrichten, 17 September 2000 Mayer H.W., "Sparen mit direkter Benzi-neinspritzung", VDI Nachrichten, 14 Sep-tember 2001

Bauer E., "Klappe auf - Schwefel tot", RobertBosch GmbH. Jerzembek M., "Enhanced performance, lower consumption", BMW Magazine, BMW New Zealand and POL Corporate Publ. Pty. Ltd., 2/2001.

Bartsch C., "Clou ist die Mechanik", VDI Nachrichten, 7 September 2001.

Weidenhammer P., "BMW setzt mit neuen Motoren hohe Ma stäbe", VDI Nachtrichten,6 Oktober 2000. 